\title{
COMPARISON OF OPTICAL AND ULTRASOUND BIOMETRY MEASUREMENTS IN EMMETROPIC AND MYOPIC EYES
}

\author{
El Saman, I. ${ }^{(*)} \&$ Mostafa, E. \\ Ophthalmology dept., Faculty of Medicine, Sohag Univ., Sohag, Egypt \\ *E-mail: eslamsaad@med.sohag.edu.eg
}

\begin{abstract}
Purpose: to compare optical biometer (IOL Master) and ultrasound biometry in emmetropic and myopic eyes as regards the measurements of axial length $(A L)$, anterior chamber depth $(A C D)$ and intraocular lens (IOL) power. Methods: Ocular biometry of cataract patients was measured by the ultrasound biometry (Sonomed PACSCAN 300A) and optical biometer (IOLMaster (Carl Zeiss Meditec, AG, Jena, Germany). Eyes with average axial length (AL22 -<26mm) were in group 1(177 eyes) and eyes with $A L \geq 26 \mathrm{~mm}$ were in group 2 (75 eyes). Parameters compared were axial length $(A L)$, anterior chamber depth (ACD), and IOL power using the SRK II formula in group1 and regression SRK-T formula in group2. Results: Two hundred and fifty two eyes of 252 cataract patients were evaluated with the two biometers. The mean values of the AL, ACD and IOL power differed slightly in both groups yet with strong correlation (Group 1: $r=0.995,0.960$, and 0.963, respectively; Group 2: $r=0.976,0.960$, and 0.970, respectively all $p<0.001)$. The differences were significant in $A L$ and $I O L$ power ( $p \leq 0.05$ ). The $I O L$ powers mean difference between the two devices was - 0.52D in group 1 and 0.54D in group 2. Conclusion: The IOL Master biometer showed good correlation with ultrasound biometer; the gold standard device in ocular biometry.
\end{abstract}

Keywords: Ocular biometry, Ultrasound biometry, IOL Master, Axial length, Anterior chamber depth, IOL power calculation

\section{Introduction}

Accurate biometry is a major contributing factor in the success of any cataract surgery. Due to the rising patients' expectations as regards sharp vision post surgery, extreme caution in calculation of biometry is a must [1]. A diverse variety of devices are available to calculate the different variables needed for reliable measurement of the power of the implanted intraocular lens (IOL). Although these devices were developed meticulously with updated tec- hnology yet they still yield imperfect and sometimes erroneous readings, in addition, it cannot be used interchangeable in most of the cases [2]. Currently, there are 2 methods for calculation of IOL power: the A-scan ultrasound and the optical biometry. The ultrasound biometry has been the gold standard method for IOL calculations for decades [3]. This method is operator- dependant as it is affected by the positioning of the probe on the center of the cornea. In 
addition it is can be a source of infection as it is a contact method [4]. Ultrasound biometry uses the applanation method which can cause erronoumous reading due to indentation of the cornea [5]. Then emerged the non contact optical biometry which uses partial coherence laser interferometry [6]. This method offers more precise (0.3$10 \mu \mathrm{m})$ and higher resolution $(12 \mu \mathrm{m})$ measurement of intraocular distance [7]. The reliable axial length measurement is attributed to using an illuminating light for fixation which is of utmost advantage in cases of staphyloma of high myopia. Optical biometry also proved superior in cases of silicon filled eyes and pseudophkia. Yet their readings are compromised where

\section{Patients and methods}

This is a comparative cross sectional prospective study of 252 patients scheduled for phacoemulsification cataract surgery in Sohag University Hospital between January - March 2018. Patients underwent biometry performed with 2 methods starting with the non contact partial coherence laser interferometry (PCI) system; the IOL Master 500 (Carl Zeiss Meditec AG, Jena, Germany). The IOLMaster acquires 10 readings for each parameter, and uses the mean. Readings could be obtained in only 180 patients and the rest were excluded due to the density of the cataract which interfered with measuring. Then 5 readings of A-scan applanation ultrasound (Sonomed PACSCAN 300A) were acquired to eliminate the effect of indentation of the probe. All measurements were performed on one eye of each patient by one physician (I.S). Exclusion criteria included: patients with corneal pathology, previous intraocular or corneal surgery or ocular trauma or systemic diseases, such as diabetes and connective tissue disease. Patients with complicated cataracts related to chronic uveitis, or silicone oil, were excluded as well. Written informed consent was obtained from all patients before any measurements, in accordance with the Declaration of He- patient cannot maintain fixation as dense opacity along the visual axis as corneal opacity, dense posterior subcapsular cataract or vitreous hemorrhage $[8,9]$. The IOL Master (Carl Zeiss Meditec AG, Jena, Germany) was the first device that performed AL measurements with automated keratometry and anterior chamber depth (ACD) measurements in 1 machine with high precision and excellent resolution [7,10-12]. In our locality where the ultrasound biometry is more available due to economic reasons, the purpose of this study was to compare the ultrasound and optical biometry in both emmetrope and myopic eyes to detect if one device can replace another.

1sinki, and the procedures were approved by the local Ethics Committee of Sohag University Hospital. A drop of topical anesthetic, benoxinate HCL $0.4 \%$, was applied before acquisition of measurements. The IOL Master 500 (Carl Zeiss Meditec AG, Jena, Germany) was focused and aligned using the image of the eye on the computer monitor while the patient was asked to fix gaze on the device's internal illuminated targets. Patients were asked to blink just before measurements were taken to avoid tear film irregularities. The IOL Master uses a modified Michelson Interferometer for measuring $\mathrm{AL}$ with precision; this creates a pair of coaxial 780-nm infrared light beams with a coherence length of about $130 \mathrm{~nm}$ which increased precision from $0.10 \mu \mathrm{m}$ (with ultrasound scan) to 0.01 to $0.02 \mu \mathrm{m}$ [13]. It also measures the central corneal power by automated keratometry, using image analysis of the distance between 3 opposite pairs of light spots, arranged in a $2.3-\mathrm{mm}$ diameter hexagonal pattern, reflected from the air-tear film interface [11]. Five separate measurements were averaged for both AL and corneal curvature, whereas a single automatically generated scan provided 5 measurements of ACD, which were then averaged. Then ultrasound 
biometry measurement was acquired taking into consideration aligning the transducer probe along the optical axis and to exert minimal corneal pressure. The mean was calculated from five measurements taken

\section{Statistical Analysis}

Data was analyzed using IBM SPSS version 19. Data was represented as mean, standard deviation and range. Pearson's correlation was used to determine relationships between the groups. Data between the devices were compared using the $\mathrm{t}$ -

\section{Results}

A cross sectional study of 252 eyes (252 patients: 133 males and 119 females) was conducted on patients undergoing cataract extraction in Sohag University Hospital. Mean age was $56.35 \pm 13.15$ years (range 34 to 79 years). Eyes with average axial length were in group 1(177 eyes) and eyes with AL >26mm were in group 2 (75 eyes). On comparing keratometry (flat and steep meridian) in group 1 by both the Topcon autokeratometer and IOL Master (Kf: 44.30 $\pm 1.73,44.17 \pm 1.74$ (P value: $0.001 ; \mathrm{r}=0.966)$; Ks: 45.53 $\pm 2.02,45.63 \pm$ 2.08 (P value: $0.002 ; r=979)$ respectively). In group 2 the flat and steep $\mathrm{K}$ were (Kf: 43.90 \pm 2.09 , 43.94 \pm 2.22 (P value: 0.03; $\mathrm{r}=0.961)$; Ks: 45.25 $\pm 2.14,45.48 \pm 2.29$ ( $\mathrm{P}$ value: $0.01 ; \mathrm{r}=0.976$ ) respectively). Keratometry readings with both the Topcon autokeratometer and IOL Master were statistically significant and well correlated. As regard the axial length and IOL power calculation, it also proved significantly for each eye. Keratometry values (power of corneal front surface in the flat $(\mathrm{kf})$ and steep meridian (ks)) were measured separately with

test, and Bland-Altman graphs were used to show measurement differences of mean values. Bland-Altman graphs were also used to assess the agreement of measurements between the two devices. A value of $p$ $<0.05$ was considered statistically significant

different in both groups, tab. (1). IOL Master showed higher values as regards the AL and IOL power. The AL was $30 \mu \mathrm{m}$ higher in the emmetrope eyes and $80 \mu \mathrm{m}$ in myopic eyes. The IOL power difference was just above $0.50 \mathrm{D}$ in both groups. Yet ACD was not different between both methods of measurement. The mean differences and $95 \%$ limits of agreement obtained using both devices are shown in tab. (2). The agreement of the ocular parameters derived from both biometry devices was high in both groups except ACD in myopic eyes. Bland-Altman plots were used to define the range encompassing most differences between the measurements by two devices, the $95 \%$ limits of agreement (mean difference $\pm 1.96 \mathrm{SD}$ ), were calculated to plot the graphs. The Bland-Altman plots, fig. (1) showed that the limits of agreement between the 2 devices remained narrow over all parameters examined.

Table (1) The mean values obtained with the two devices

\begin{tabular}{|c|c|c|c|c|c|c|c|c|}
\hline & \multicolumn{4}{|c|}{ Group 1 (average eyes) } & \multicolumn{4}{|c|}{ Group 2 (Myopic eyes) } \\
\hline & $\begin{array}{c}\text { Ultrasound } \\
\text { biometry }\end{array}$ & $\begin{array}{c}\text { Optical } \\
\text { biometry }\end{array}$ & $\begin{array}{c}P \\
\text { value }\end{array}$ & $\begin{array}{c}r \\
\text { Value }\end{array}$ & $\begin{array}{c}\text { Ultrasound } \\
\text { biometry }\end{array}$ & $\begin{array}{c}\text { Optical } \\
\text { biometry }\end{array}$ & $\begin{array}{c}P \\
\text { value }\end{array}$ & $\begin{array}{c}r \\
\text { Value }\end{array}$ \\
\hline $\mathbf{A L}$ & $\begin{array}{l}23.18 \pm 1.16 \\
20.49: 25.99\end{array}$ & $\begin{array}{l}23.21 \pm 1.15 \\
20.47: 25.85\end{array}$ & 0.01 & 0.995 & $\begin{array}{l}28.95 \pm 1.81 \\
26.02: 33.21\end{array}$ & $\begin{array}{l}29.03 \pm 1.88 \\
26.11: 33.56\end{array}$ & 0.05 & 0.976 \\
\hline ACD & $\begin{array}{c}4.85 \pm 5.24 \\
2.35: 23.5\end{array}$ & $\begin{array}{c}4.58 \pm 5.07 \\
2.04: 26\end{array}$ & 0.17 & 0.960 & $\begin{array}{c}3.61 \pm 0.62 \\
2.87: 6.0\end{array}$ & $\begin{array}{c}3.64 \pm 0.31 \\
2.94: 4.5\end{array}$ & 0.61 & 0.09 \\
\hline $\begin{array}{l}\text { IOL } \\
\text { power }\end{array}$ & $\begin{array}{c}18.57 \pm 5.84 \\
2.63: 29\end{array}$ & $\begin{array}{c}19.03 \pm 5.94 \\
2.72: 29\end{array}$ & 0.002 & 0.963 & $\begin{array}{l}3.78 \pm 5.06 \\
-12.5: 12.5\end{array}$ & $\begin{array}{l}3.24 \pm 6.04 \\
-18.5: 13.0\end{array}$ & 0.007 & 0.97 \\
\hline
\end{tabular}

$\boldsymbol{A L}$, axial length; $\boldsymbol{A C D}$, anterior chamber length; $\mathbf{I O L}$, intraocular lens. 
Table (2) The mean differences, SD, and limits of agreement between the four parameters obtained with the optical and ultrasound biometry

\begin{tabular}{|l|c|c|c|c|c|c|}
\hline & \multicolumn{2}{c}{ Group 1 (average eyes) } & \multicolumn{2}{c|}{ Group 2 (Myopic eyes) } \\
& $\begin{array}{c}\text { Mean } \\
\text { differences }\end{array}$ & SD & $\begin{array}{c}\text { 95 \% limits of } \\
\text { agreement }\end{array}$ & $\begin{array}{c}\text { Mean } \\
\text { differences }\end{array}$ & SD & $\begin{array}{c}\text { 95 \% limits of } \\
\text { agreement }\end{array}$ \\
\hline AL & -0.03 & 0.16 & $-0.34: 0.28$ & -0.08 & 0.40 & $-0.34: 0.28$ \\
\hline ACD & 0.21 & 2.03 & $-3.86: 4.28$ & -0.04 & 0.67 & $-1.37: 1.29$ \\
\hline IOL Power & -0.52 & 2.22 & $-4.96: 3.92$ & 0.54 & 1.64 & $-4.96: 3.92$ \\
\hline
\end{tabular}

AL, axial length; $A C D$, anterior chamber length; IOL, intraocular lens.

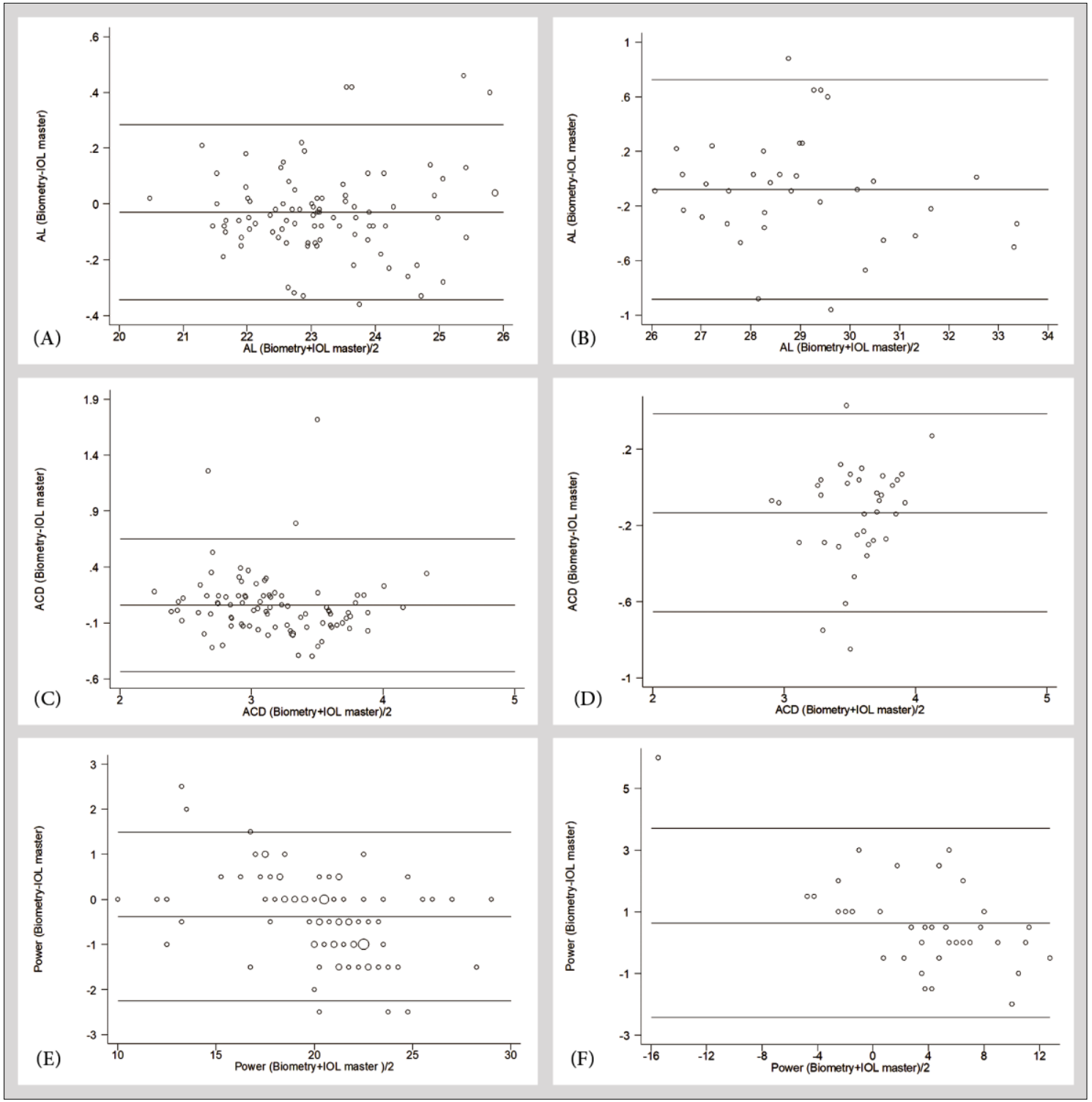

Figure (1) Bland-Altman plots

\section{Discussion}

Axial length measurements derive its importance from the fact that an error of $100 \mu \mathrm{m}$ in axial length measurement could affect the postoperative refractive state by $0.28 \mathrm{D}$ [14]. Biometry performed using A-scan ultrasonography has a longit- udinal resolution of $200 \mathrm{~m}$ and an accuracy of $100-120 \mu \mathrm{m}$ in measuring axial lengths [15]. While optical biometry using the principle of partial coherence laser interferometry (PCLI) has a high resolution $(12 \mu \mathrm{m})$ and precision $(0.3-10 \mu \mathrm{m})[7,16]$. 
Partial coherence laser interferometry offers the advantages of noncontact approach of measurement along with the ease of obtaining keratometry, ACD and AL measurements in a single sitting. Contrary to the conventional ultrasound biometry, which necessitates topical anaesthesia for corneal applanation and is time consuming [5]. Since partial coherence laser interferometry needs adequate foveal fixation. Thus eyes with corneal scarring, macular degeneration, and eccentric fixation were excluded from the start. We report 20\% failure to acquire readings using IOL Master, which is higher than other studies [12]. This can be attributed to the fact of predominance of hard cataract in our locality and late patient presentation to ask for medical help. Our results show that there is a tendency for longer AL values by IOL Master in both average and myopic eyes (30 $\mu \mathrm{m}$ and $80 \mu \mathrm{m}$ respectively). This leads to hyperopic shift in IOL power calculation which draws attention that both devices should not be used interchangeably. There was good agreement and correlation of IOL power derived by both devices. The mean difference was 0.52 diopter (D) in emmetrope eyes and quite similar value in myopic eyes $(0.54 \mathrm{D})$ which is merely above the increment in the IOL power step $(0.50 \mathrm{D})$. The chosen IOL formula in both groups was different according to the best one according to the axial length. The longer AL by optical biometry can be contributed to: the absence of indentation of the cornea and the difference between the physical principles of the two devices. Ultrasound is reflected from the internal limiting membrane, whereas PCI is reflected from the retinal pigment epithelium [17]. Ultrasound does not depend on patient fixation; it measures the anatomical length of the eye, from the corneal vertex to the posterior pole, whereas the PCI measures the optical length. Although the anatomical length that is measured with ultrasound biometry measures is almost always longer than the optical length [18], the AL measurements determined with PCI technology are frequently reported to be longer because of the explanations mentioned above. In high myopia, the difference between the anatomical and optical length is increased [19], and this can be a possible explanation for the longer AL measurements obtained with ultrasound in some studies. Accommodation might also influence $\mathrm{AL}$ measurements and thus IOL calculations as stated by some studies [20, 21]. There are a myriad of studies with conflicting results as regards the agreement of both devices. Buckhurst et al [22]. reported a shorter mean AL with the Lenstar than the ultrasonic biometry which was opposite to the results by Cruysberg et al [23]. As for IOL Master studies, the AL measurements obtained with PCI technology were longer than those obtained with the ultrasonic biometry [24,25]. While Santodomingo et al [11] reported no significant difference in the AL between the two devices in normal healthy eyes. Studies comparing two optical biometer; IOL Master and Lenstar; Lenstar showed slightly but statistically longer AL than IOLMaster [22, 23]. Lower ACD values with the ultrasonic biometry are expected due to the indentation of the cornea by the ultrasound probe. A study by Buckhurst et al [22] showed ACD measurements increasing by $0.32 \mathrm{~mm}$ with the Lenstar. While Lara et al [26] found a $0.16 \mathrm{~mm}$ increase only mean ACD value. Shorter ACD measurements obtained with ultrasound compared to those obtained with the IOL Master have also been reported [27]. If the required IOL power is considered to vary by $0.1 \mathrm{D}$ for each 0.2 $\mathrm{mm}$ of ACD [28] $0.27 \mathrm{~mm}$ difference is not clinically significant. In addition, the non-contact feature of the Lenstar eliminates possible corneal indentation as a source of measurements error and eliminates the risk of the transmission of infections. 
Although ultrasound biometry has been used as the gold standard for the measurement of $\mathrm{AL}$ in our locality, yet the introduction of IOL Master is increasingly replacing the conventional method and giving rise to a debate of whether the new technology should replace the old one entirely. Yet a well-known disadvantage of PCI technology is its inability to obtain measurements in eyes with dense cataracts and those that cannot fixate on the red light of the device because of inadequate vision which are prevalent in our locality. This study has some limitations. Further studies are needed to compare both devices in healthy, pseudophakic, aphakic and silicone filled eyes as well as short eyes. We are also aware that postoperative refractive state of these patients would have added a value to our study. Yet the attempt was to focus on the measuring differences of different parameters of both devices. In addition, the predicted refractive state would have depended on the surgeon's choice of rendering the patient emmetrope or slightly myope.

\section{Conclusion}

There were statistically significant differences in AL and IOL power calculation between the IOL Master and the ultrasound biometer. Yet, all the parameters obtained by the IOL Master and the ultrasound biometry were significantly correlated with each other. The differences were clinically insignificant for the $A C D$. Greater $A L$ and $A C D$ values were obtained with the IOL Master. Therefore, the values obtained by these different devices cannot be used interchangeably. In our locality where denser cataracts prevail, ultrasound biometry is indispensible yet the availability of an optical biometry would add value in faint cataracts and in myopic eyes.

\section{References}

1. Norrby S. Sources of error in intraocular lens power calculation. J Cataract Refract Surg 2008; 34 (3): 368-76.

2. Rozema J., Wouters K., Mathysen D., et al. Overview of the repeatability, reproducibility, and agreement of the biometry values provided by various ophthalmic devices. Am J Ophthalmol. 2014; 158 (6): 1111-1120.

3. Zhong J., Shao Y., Tao A., et al. Axial biometry of the entire eye using ultralong scan depth optical coherence tomography. Am J Ophthalmol 2014; 157 (2): 412-420.

4. Hamidzada W., Osuobeni E. Agreement between A-mode and B-mode ultrasonography in the measurement of ocular distances. Vet Radiol Ultrasound 1999; 40 (5): 502-507.

5. Norrby S, Lydahl E., Koranyi G, et al. Comparison of 2 A-scans. J Cataract Refract Surg. 2003; 29 (1): 95-99.

6. Drexler W., Baumgartner A., Findl O., et al. Submicrometer precision biometry of the anterior segment of the human eye. Invest Ophthalmol Vis Sci 1997; 38 (7): 1304-1313.

7. Drexler W., Findl O., Menapace R., et al. Partial coherence interferometry: A novel approach to biometry in cataract surgery. Am J Ophthalmol 1998; 126 (4): 524-534.

8. Tehrani M., Krummenauer F., Blom E., et al. Evaluation of the practicality of optical biometry and applanation ultrasound in 253 eyes. J Cataract Refract Surg. 2003; 29 (4): 741-746.

9. Parravano M., Oddone F., Sampalmieri M., et al. Reliability of the IOLMaster in axial length evaluation in silicone oilfilled eyes. Eye (Lond). 2007; 21 (7): 909-911.

10. Haigis W., Lege B., Miller N., et al. Comparison of immersion ultrasound biometry and partial coherence interferometry for intraocular lens calculation according to Haigis. Graefes Arch Clin Exp Ophthalmol. 2000; 238 (9): 765-773.

11. Santodomingo-Rubido J., Mallen E., Gilmartin B., et al. A new non-contact 
optical device for ocular biometry. $\mathbf{B r}$ J Ophthalmol. 2002; 86 (4): 458-462.

12. Kiss B., Findl O., Menapace R., et al. Biometry of cataractous eyes using partial coherence interferometry: Clinical feasibility study of a commercial prototype I. J Cataract Refract Surg 2002; 28 (2): 224-229.

13. Garg A., Lin J. Latkany R., et al. Mastering the techniques of IOL power calculations, $2^{\text {nd }}$ ed. Jaypee Brothers Medical Publishers Pte Ltd NY, 2009.

14. Olsen T. Theoretical approach to intraocular lens calculation using Gaussian optics. J Cataract Refract Surg 1987; 13 (2): 141-145.

15. Bamber J. Diagnostic ultrasound, Ch 7, In: Webb S. ed. The physics of medical imaging, Adam Hilger, Philadelphia, 1988, pp. 319-388

16. Hitzenberger C., Drexler W., Dolezal C., et al. Measurement of the axial length of cataract eyes by laser doppler interferometry. Invest Ophthalmol Vis Sci. 1993; 34 (6): 1886-1893.

17. Hussin H., Spry P., Majid M., et al. Reliability and validity of the partial coherence interferometry for measurement of ocular axial length in children. Eye (Lond). 2006; 20 (9): 1021-1024.

18. Landers J., Goggin M. Comparison of refractive outcomes using immersion ultrasound biometry and IOL Master biometry. Clin Exp Ophthalmol. 2009; 37 (6): 566-569.

19.Zaldivar R., Shultz M., Davidorf J., et al. Intraocular lens power calculations in patients with extreme myopia. J Cataract Refract Surg 2000; 26 (5): 668-674.

20. Read S., Collins M., Woodman E., et al. Axial length changes during accom- modation in myopes and emmetropes. Optom Vis Sci. 2010; 87 (9): 656-662.

21. Mallen E., Kashyap P., Hampson K. Transient axial length change during the accommodation response in young adults. Invest Ophthalmol Vis Sci. 2006; 47 (3): 1251-1254.

22. Buckhurst P., Wolffsohn J., Shah S., et al. A new optical low coherence reflectometry device for ocular biometry in cataract patients. Br J Ophthalmol. 2009; 93 (7): 949-953.

23. Cruysberg L., Doors M., Verbakel F., et al. Evaluation of the lenstar LS 900 non-contact biometer. Br J Ophthalmol. 2010; 94 (1): 106-110.

24. Kielhorn I., Rajan M., Tesha P., et al. Clinical assessment of the Zeiss IOL Master. J Cataract Refract Surg. 2003; 29 (3): 518-522.

25. Goyal R., North R., Morgan J. Comparison of laser interferometry and ultrasound A-scan in the measurement of axial length. Acta Ophthalmol Scand. 2003; 81 (4): 331-335.

26. Lara F., Fernandez-Sanchez V., LopezGil N., et al. Comparison of partial coherence interferometry and ultrasound for anterior segment biometry. J Cataract Refract Surg. 2009; 35 (2): 324-329.

27. Reddy A., Pande M., Finn P., et al. Comparative estimation of anterior chamber depth by ultrasonography, Orbscan II, and IOL Master. J Cataract Refract Surg. 2004; 30 (6): 1268-1271.

28. Lackner B., Schmidinger G., Skorpik C. Validity and repeatability of anterior chamber depth measurements with Pentacam and Orbscan. Optom Vis Sci. 2005; 82 (9): 858-861. 